ARTICLE

Received 4 Feb 2015 | Accepted 18 Jun 2015 | Published 10 Aug 2015

DOI: $10.1038 /$ ncomms 8890

OPEN

\title{
Hydride bridge in [NiFe]-hydrogenase observed by nuclear resonance vibrational spectroscopy
}

Hideaki Ogata ${ }^{1, \star}$, Tobias Krämer ${ }^{1, \star}$, Hongxin Wang ${ }^{2,3, \star}$, David Schilter $^{4, *, \dagger}$, Vladimir Pelmenschikov $^{5, \star}$, Maurice van Gastel ${ }^{1}$, Frank Neese ${ }^{1}$, Thomas B. Rauchfuss ${ }^{4}$, Leland B. Gee ${ }^{2}$, Aubrey D. Scott ${ }^{2}$, Yoshitaka Yoda ${ }^{6}$, Yoshihito Tanaka ${ }^{7} \dagger$, Wolfgang Lubitz ${ }^{1} \&$ Stephen P. Cramer ${ }^{2,3}$

The metabolism of many anaerobes relies on [NiFe]-hydrogenases, whose characterization when bound to substrates has proven non-trivial. Presented here is direct evidence for a hydride bridge in the active site of the ${ }^{57} \mathrm{Fe}$-labelled fully reduced $\mathrm{Ni}-\mathrm{R}$ form of Desulfovibrio vulgaris Miyazaki $\mathrm{F}$ [NiFe]-hydrogenase. A unique 'wagging' mode involving $\mathrm{H}^{-}$motion perpendicular to the $\mathrm{Ni}(\mu-\mathrm{H})^{57} \mathrm{Fe}$ plane was studied using ${ }^{57} \mathrm{Fe}$-specific nuclear resonance vibrational spectroscopy and density functional theory (DFT) calculations. On $\mathrm{Ni}(\mu-\mathrm{D})^{57} \mathrm{Fe}$ deuteride substitution, this wagging causes a characteristic perturbation of $\mathrm{Fe}-\mathrm{CO} / \mathrm{CN}$ bands. Spectra have been interpreted by comparison with $\mathrm{Ni}(\mu-\mathrm{H} / \mathrm{D})^{57} \mathrm{Fe}$ enzyme mimics $\left[(\mathrm{dppe}) \mathrm{Ni}(\mu-\mathrm{pdt})(\mu-\mathrm{H} / \mathrm{D})^{57} \mathrm{Fe}(\mathrm{CO})_{3}\right]^{+}$and DFT calculations, which collectively indicate a low-spin $\mathrm{Ni}(\|)(\mu-\mathrm{H}) \mathrm{Fe}(\|)$ core for $\mathrm{Ni}-\mathrm{R}$, with $\mathrm{H}^{-}$binding $\mathrm{Ni}$ more tightly than $\mathrm{Fe}$. The present methodology is also relevant to characterizing $\mathrm{Fe}-\mathrm{H}$ moieties in other important natural and synthetic catalysts.

\footnotetext{
${ }^{1}$ Max Planck Institute for Chemical Energy Conversion, Mülheim an der Ruhr 45470, Germany. ${ }^{2}$ Department of Chemistry, University of California, Davis, California 95616, USA. ${ }^{3}$ Division of Physical Biosciences, Lawrence Berkeley National Laboratory, Berkeley, California 94720, USA. ${ }^{4}$ Department of Chemistry, University of Illinois, Urbana, Illinois 61801, USA. ${ }^{5}$ Institut für Chemie, Technische Universität Berlin, Berlin 10623, Germany. ${ }^{6}$ Division of Research and Utilization, SPring-8/JASRI, Hyogo 679-5198, Japan. ${ }^{7}$ Materials Dynamics Laboratory, RIKEN SPring-8, Hyogo 679-5148, Japan. ${ }^{*}$ These authors contributed equally to this work. †Present address: IBS Center for Multidimensional Carbon Materials, Ulsan National Institute of Science and Technology, Ulsan 689-798, Republic of Korea (D.S.); Graduate School of Material Science, University of Hyogo, Hyogo 678-1297, Japan (Y.T.). Correspondence and requests for materials should be addressed to S.P.C. (email: spjcramer@ucdavis.edu).
} 
A central goal of the hydrogen economy is to forestall a continual buildup of $\mathrm{CO}_{2}$ and the threat of global climate change ${ }^{1}$. However, achieving independence of carbonbased fuels necessitates the development of better $\mathrm{H}_{2}$-processing catalysts from earth-abundant materials. In this regard, bidirectional hydrogenase enzymes, which catalyse both production and consumption of $\mathrm{H}_{2}$ (refs 2,3), have attracted interest either for direct utilization ${ }^{4}$ or as aspirational targets for biomimetic catalysts ${ }^{5-11}$.

The redox-active hydrogenases are classified as either [FeFe]or [NiFe]-hydrogenase, according to the metals present at their active sites. While both types possess high catalytic activity ${ }^{12-14}$, the latter are attractive practically in that they are more $\mathrm{O}_{2}$ tolerant ${ }^{12,15}$. The $[\mathrm{NiFe}]$-hydrogenase active site features $\mathrm{Ni}$ and Fe centres bridged by two Cys residues (Fig. 1a), with two further Cys ligands binding $\mathrm{Ni}$ terminally, and the $\mathrm{Fe}$ coordination sphere being completed by one $\mathrm{CO}$ and two $\mathrm{CN}^{-}$groups. The $[\mathrm{NiFe}]$ site functions in concert with an electron transport chain comprising three $\mathrm{Fe}-\mathrm{S}$ clusters. The catalytic cycle is generally thought to involve three key redox states of the bimetallic centre: electron spin (paramagnetic) resonance (EPR)-silent Ni-SI, EPRactive $\mathrm{Ni}-\mathrm{C}$ and another EPR-silent species known as $\mathrm{Ni}-\mathrm{R}^{16-18}$. Despite progress in characterizing hydrogenases by crystallography, spectroscopy, and theory ${ }^{16}$, questions remain about the molecular and electronic structure of various intermediates and inhibited species. This particularly applies to the electronic structure of Ni-R.

$\mathrm{Up}$ to three isoelectronic $\mathrm{Ni}$ (II)Fe(II) forms of $\mathrm{Ni}-\mathrm{R}$ are characterized by their $\mathrm{pH}$-dependent Fourier transform infrared (FT-IR) signatures ${ }^{18}$. The structures proposed for these Ni-R subspecies (Fig. 1b-d) most commonly have a bridging hydride at the active site $(\mathrm{Ni}(\mu-\mathrm{H}) \mathrm{Fe})^{19-22}$, with some even featuring an additional (terminal) hydride at $\mathrm{Ni}(\mathrm{HNi}(\mu-\mathrm{H}) \mathrm{Fe})^{23,24}$. Another suggested form has an Fe-bound dihydrogen ligand $\left(\mathrm{NiFe}\left(\eta^{2}-\right.\right.$ $\left.\left.\mathrm{H}_{2}\right)\right)^{25,26}$. A recent high-resolution crystallographic analysis of $\mathrm{Ni}-\mathrm{R} 1$, a subspecies of $\mathrm{Ni}-\mathrm{R}$, indicates a $\mathrm{Ni}(\mu-\mathrm{H}) \mathrm{Fe}$ core with a protonated terminal cysteinate ${ }^{27}$. Among proposals supporting the bridging hydride, there is further debate as to whether $\mathrm{H}^{-}$is bound more strongly to $\mathrm{Fe}$ or $\mathrm{Ni}$ (ref. 28) and whether $\mathrm{Ni}$ (II) is high $^{29}$ or low spin ${ }^{30}$ or whether both spin configurations coexist in the bulk ${ }^{31,32}$.
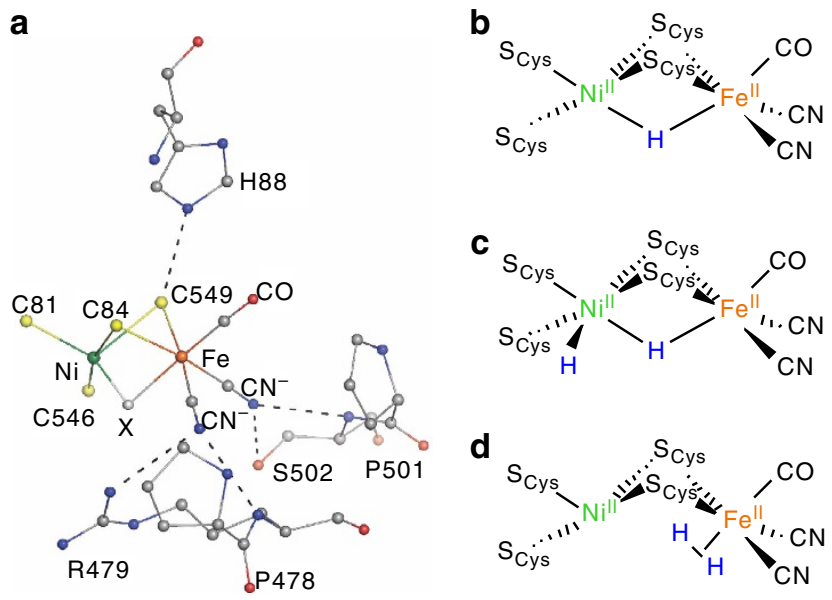

Figure 1 | The $\mathbf{N i}-\mathbf{R}$ reduced state of [NiFe]-hydrogenase. (a) X-ray structure of the Desulfovibrio vulgaris Miyazaki F (DvMF) [NiFe]hydrogenase active site from PDB entry 1WUI (ref. 62). The bridging ligand $\mathrm{X}$ is oxygenic for deactivated states, with catalytically active states having either a hydride or a vacant site. (b-d) Some of the structures proposed for isoelectronic Ni-R forms ${ }^{19-26}$.
The Ni-R state represents a special challenge for spectroscopy in that it is EPR-silent, photolabile (and thus difficult to study with Raman spectroscopy) and expected to feature an active site $\mathrm{M}-\mathrm{H}$ moiety (being notoriously difficult to observe using infrared methods) ${ }^{33}$. The present study instead employs a synchrotron radiation technique called nuclear resonance vibrational spectroscopy (NRVS), which involves X-ray excitation of a Mössbauer-active nuclide ${ }^{34-37}$. The raw NRVS data are commonly translated into partial vibrational density of states (PVDOS) spectra ${ }^{38}$, which show vibrational energy contributions specifically from the Mössbauer-active nuclei, such as ${ }^{57} \mathrm{Fe}$. PVDOS can also be predicted using density functional theory (DFT) or empirical force field calculations, assisting in confident spectral assignments.

NRVS is uniquely suited to detailed investigations of ${ }^{57} \mathrm{Fe}$ labelled enzyme active sites, avoiding interference from the thousands of protein modes present in a typical infrared or Raman spectrum. NRVS has enabled the observation of $\mathrm{Fe}-\mathrm{CN}$ and $\mathrm{Fe}-\mathrm{CO}$ bending and stretching modes for the active sites in [NiFe]-hydrogenases ${ }^{39,40}$, despite the presence of 11 (or more) Fe centres in clusters of the electron transport chain. This is because $\mathrm{Fe}-\mathrm{CN}$ and $\mathrm{Fe}-\mathrm{CO}$ modes are strongest in the region from 440 to $640 \mathrm{~cm}^{-1}$, while $\mathrm{Fe}-\mathrm{S}$ cluster modes only make significant contributions below $440 \mathrm{~cm}^{-1}$ (refs 41-43). Another recent application of NRVS to a trans-H/D- ${ }^{57} \mathrm{Fe}-(\mathrm{CO})$ compound shed light on coupling of $\mathrm{Fe}-\mathrm{H} / \mathrm{D}$ and $\mathrm{Fe}-\mathrm{CO}$ bending modes ${ }^{33}$.

The present study discloses the first spectroscopic evidence for the bridging hydride in the $\mathrm{Ni}-\mathrm{R}$ active site and the unprecedented NRVS observation of a $\mathrm{Fe}-\mathrm{H}$ stretching mode in a synthetic $\mathrm{Ni}-\mathrm{H}-\mathrm{Fe}$ system. A combined experimental/theoretical analysis of both $\mathrm{Ni}-\mathrm{R}$ and its synthetic mimics is presented here, an approach that we anticipate to be of broad utility for the characterization of (bio)inorganic Fe-hydride catalysts.

\section{Results}

NRVS of model complexes. The $\mathrm{Ni}(\mathrm{II})(\mu \text {-thiolate })_{2}(\mu$-H)Fe(II) core proposed for $\mathrm{Ni}-\mathrm{R}$ is reproduced by the diamagnetic $\mathrm{H}_{2}$-evolving catalyst $\left[(\mathrm{dppe}) \mathrm{Ni}(\mu \text {-pdt })(\mu-\mathrm{H}) \mathrm{Fe}(\mathrm{CO})_{3}\right]^{+}\left([\mathbf{1 H}]^{+}\right.$, dppe $=1,2$-bis (diphenylphosphino)ethane $=1,2-\mathrm{Ph}_{2} \mathrm{PCH}_{2} \mathrm{CH}_{2} \mathrm{P}$ $\mathrm{Ph}_{2}, \quad \mathrm{pdt}^{2-}=1,3$-propanedithiolate $\left.={ }^{-} \mathrm{SCH}_{2} \mathrm{CH}_{2} \mathrm{CH}_{2} \mathrm{~S}^{-}\right)^{44,45}$ shown in Fig. 2a, which has recently been studied using resonance Raman spectroscopy ${ }^{46}$. Synthetic methodology allowed the preparation of the labelled analogue $[(\mathrm{dppe}) \mathrm{Ni}(\mu-\mathrm{pdt})(\mu-\mathrm{H} / \mathrm{D})$ $\left.{ }^{57} \mathrm{Fe}(\mathrm{CO})_{3}\right]^{+}$in both hydride $\left[\mathbf{1}^{\prime} \mathrm{H}\right]^{+}$and deuteride $\left[\mathbf{1}^{\prime} \mathrm{D}\right]^{+}$forms for ${ }^{57} \mathrm{Fe}$ NRVS analysis (see Supplementary Figs $1-16$ and Supplementary Note 1). Complementary ${ }^{13} \mathrm{CO}$-labelled species $\left[\mathbf{1}^{\prime \prime} \mathrm{H} / \mathrm{D}\right]^{+}$were prepared as well.

The NRVS spectra for $\left[\mathbf{1}^{\prime} \mathrm{H} / \mathrm{D}\right]^{+}$are presented in Fig. $2 \mathrm{~b}$. Apart from low-frequency $\left(180-340 \mathrm{~cm}^{-1}\right) \mathrm{Fe}-\mathrm{S}$ modes, there are strong bands in the $440-630 \mathrm{~cm}^{-1}$ region assigned to $v_{\mathrm{Fe}-\mathrm{CO}}$ stretches and $\delta_{\mathrm{Fe}-\mathrm{CO}}$ bends (Supplementary Table 1 ). On the high-energy side, NRVS analysis of $\left[\mathbf{1}^{\prime} \mathrm{H}\right]^{+}$also reveals peaks at 1,532 and $1,468 \mathrm{~cm}^{-1}$ that have previously been assigned to $v_{\mathrm{Fe}-\mathrm{H}}$ modes of two different conformations of the $\mathrm{pdt}^{2-}$ ligand ('Ni/Fe-flippamers ${ }^{\text {' }}{ }^{4-50}$, see Fig. 2a and Supplementary Fig. 17 using Raman spectroscopy on $[1 \mathrm{H}]^{+}$(ref. 46, Supplementary Table 2). As expected, these features red-shift to $\sim 1,101 \mathrm{~cm}^{-1}$ on $\mathrm{D}$ substitution in the bridge. While NRVS has uncovered $\delta_{\mathrm{Fe}-\mathrm{H} / \mathrm{D}}$ (ref. 33) and $v_{\mathrm{Fe}-\mathrm{D}}$ modes $^{51}$ for other species, the 1,532 and $1,468 \mathrm{~cm}^{-1}$ bands for $\left[\mathbf{1}^{\prime} \mathrm{H}\right]^{+}$are the first $\mathrm{Fe}-\mathrm{H}$ stretching modes detected using this technique, as well as being the highestfrequency bands observed using NRVS to date. The band at $954 \mathrm{~cm}^{-1}$ for $\left[\mathbf{1}^{\prime} \mathrm{H}\right]^{+}$, previously assigned to a $v_{\mathrm{Ni}-\mathrm{H}} \operatorname{mode} \mathrm{e}^{46}$, is evidently also Fe-coupled, given its detection using NRVS. In $\left[\mathbf{1}^{\prime} \mathrm{D}\right]^{+}$, the corresponding $\mathrm{Ni}-\mathrm{D}$ stretch is at $708 \mathrm{~cm}^{-1}$. As 
a

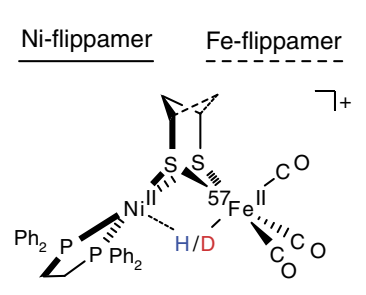

d

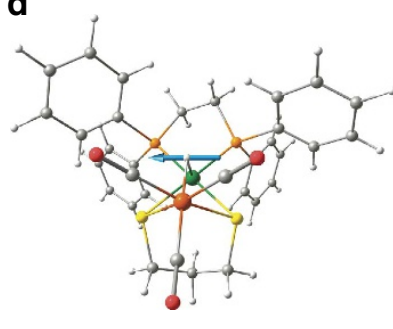

$774 \mathrm{~cm}^{-1}$ e

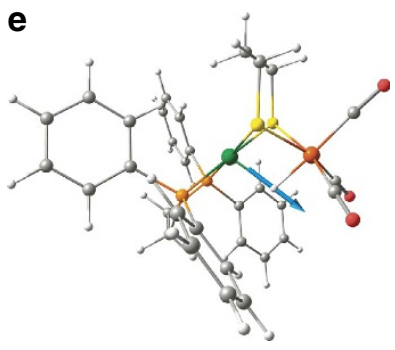

$1,022 \mathrm{~cm}^{-1}$

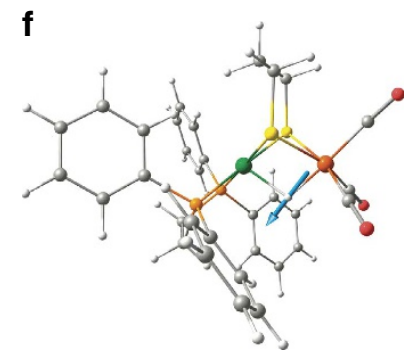

$1,479 \mathrm{~cm}^{-1}$

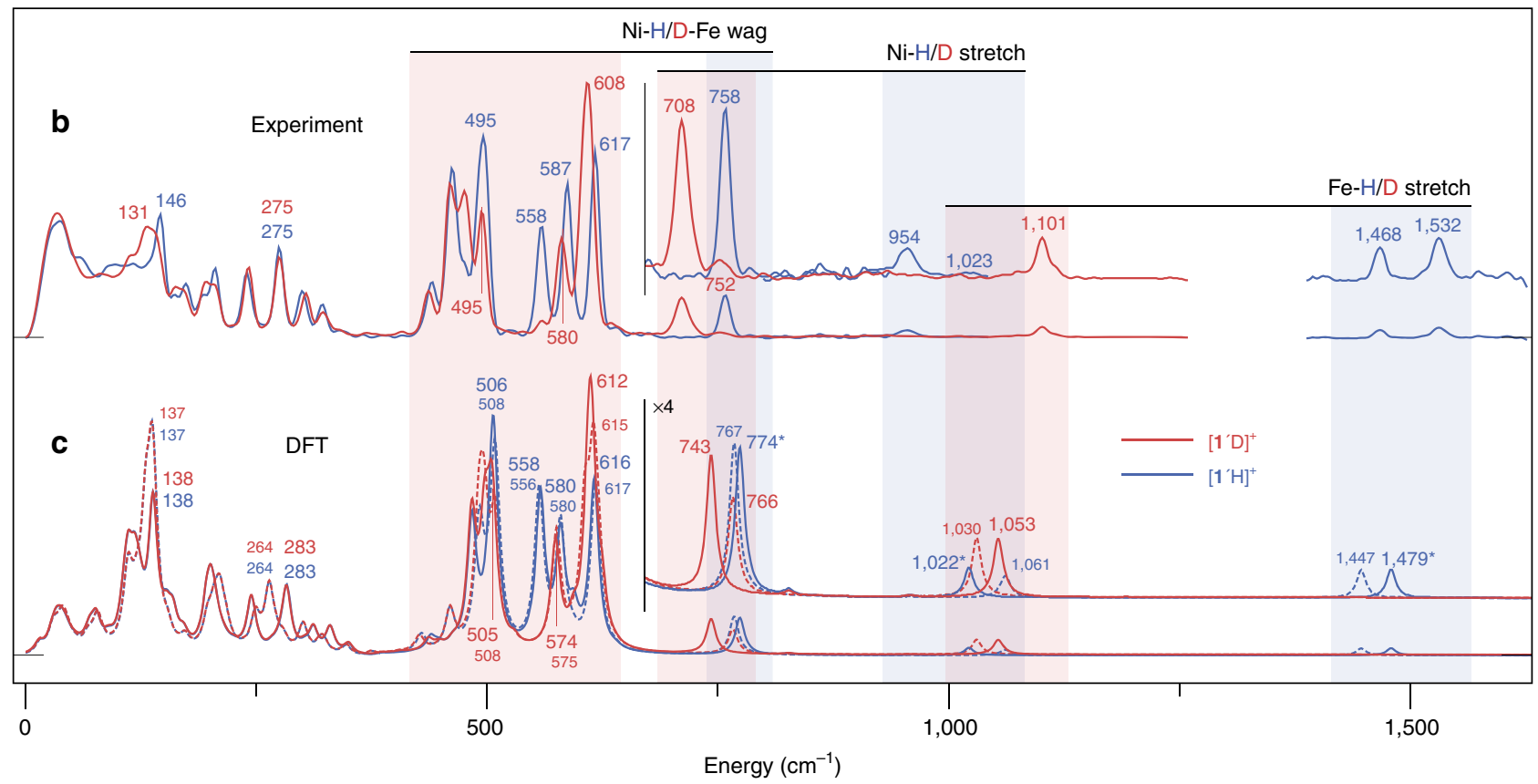

Figure 2 | Metal-hydride bands for complexes $\left[\mathbf{1}^{\prime} \mathbf{H} / \mathbf{D}\right]^{+}$. (a) Structure of $\left[\mathbf{1}^{\prime} H\right]^{+}$showing 'flippamer' conformations of the pdt ${ }^{2-}$ ligand. (b,c) Full-range ${ }^{57} \mathrm{Fe} \mathrm{PVDOS}$ for $\left[\mathbf{1}^{\prime} \mathrm{H}\right]^{+}$(blue trace) and $\left[\mathbf{1}^{\prime} \mathrm{D}\right]^{+}$(red trace) from NRVS experiments $(\mathbf{b})$ and DFT calculations $(\mathbf{c})$. In $\mathbf{c}$, the plain/broken traces are spectra calculated for the dominant/alternative Ni-/Fe-flippamer, respectively. Spectra are repeated in the region $>700 \mathrm{~cm}^{-1}$ with their intensities $\times 4$ amplified. The colour bars highlight specific M-H/D bands, as well as their shifts on isotopic substitution. (d-f) Scaled-arrow representations of the M-H normal modes calculated for the Ni-flippamer of $\left[\mathbf{1}^{\prime} \mathrm{H}\right]^{+}$are shown, with the corresponding bands indicated $\left(^{*}\right)$ in $\mathbf{c}$. Unscaled-arrow and animated representations of these $\mathrm{M}-\mathrm{H}$ modes can be found in Supplementary Fig. 22 and Supplementary Movies 1-3, respectively.

expected from a harmonic oscillator in which $\mathrm{H} / \mathrm{D}$ binds a much heavier nucleus, the $v_{\mathrm{Fe}-\mathrm{H}} / v_{\mathrm{Fe}-\mathrm{D}}$ and $v_{\mathrm{Ni}-\mathrm{H}} / v_{\mathrm{Ni}-\mathrm{D}}$ frequency ratios are $\sim 2^{1 / 2}$. This difference in the $\mathrm{H} / \mathrm{D}$ and ${ }^{57} \mathrm{Fe}$ nuclear masses also results in pure hydride bands having low NRVS intensities, as such vibrations involve only small displacements of the ${ }^{57} \mathrm{Fe}$ centre. In addition, our successful use of NRVS to detect the welldefined $v_{\mathrm{Ni}-\mathrm{D}}$ stretch in ${ }^{57} \mathrm{Fe}$-labelled $\left[\mathbf{1}^{\prime} \mathrm{D}\right]^{+}$contrasts Raman studies of natural $\mathrm{Fe}$ abundance $[1 \mathrm{DD}]^{+}$, in which the Ni-D band was obscured by solvent modes ${ }^{46}$.

On the basis of previous studies, one would expect $\delta_{\mathrm{OC}-\mathrm{Fe}-\mathrm{H} / \mathrm{D}}$ modes to appear in the $530-750 / 410-640 \mathrm{~cm}^{-1}$ regions, respectively $y^{33,46}$. The hydride $\left[\mathbf{1}^{\prime} \mathrm{H}\right]^{+}$exhibits a well-defined NRVS feature at $758 \mathrm{~cm}^{-1}$ consistent with a $\delta_{\mathrm{Fe}-\mathrm{H}}$ mode, this region being obscured by solvent bands in Raman data ${ }^{46}$. As will become clear, this $758 \mathrm{~cm}^{-1}$ mode observed for $\left[\mathbf{1}^{\prime} \mathrm{H}\right]^{+}$is of particular relevance to the interpretation of NRVS data for [NiFe]-hydrogenase. A distinct assignment for the corresponding $\delta_{\mathrm{Fe}-\mathrm{D}}$ mode in $\left[\mathbf{1}^{\prime} \mathrm{D}\right]^{+}$is prevented by its mixing with the $\mathrm{Fe}-\mathrm{CO}$ bending modes, such that the NRVS intensity is redistributed throughout the $440-630 \mathrm{~cm}^{-1}$ region.

Analysis of $\left[\mathbf{1}^{\prime} \mathrm{H}\right]^{+}$revealed several intense $\mathrm{Fe}-\mathrm{CO}$ bands in the $440-630 \mathrm{~cm}^{-1}$ region (Fig. $2 \mathrm{~b}$ ), the energies of which are almost identical to those of the conjugate base (dppe) Ni( $\mu$-pdt) ${ }^{57} \mathrm{Fe}(\mathrm{CO})_{3}\left(\mathbf{1}^{\prime}\right)^{47}$, which lacks the hydride bridge. This is exemplified by the $\delta_{\mathrm{Fe}-\mathrm{CO}}$ NRVS triplets for $\left[\mathbf{1}^{\prime} \mathrm{H}\right]^{+}(558,587$ and $617 \mathrm{~cm}^{-1}$ ) and $\mathbf{1}^{\prime}\left(557,588\right.$ and $\left.613 \mathrm{~cm}^{-1}\right)$ being virtually coincident (Supplementary Table 1), suggesting that the presence of $\mathrm{H}^{-}$does not significantly perturb the $\delta_{\mathrm{Fe}-\mathrm{CO}}$ dynamics. In contrast, the $\delta_{\mathrm{Fe}-\mathrm{CO}}$ region for $\left[\mathbf{1}^{\prime} \mathrm{D}\right]^{+}$collapses to a pair of bands at 580 and $608 \mathrm{~cm}^{-1}$, consistent with significant coupling to the $\delta_{\mathrm{Fe}-\mathrm{D}}$ bending motion. Thus, although $\mathrm{Fe}-\mathrm{D}$ modes have intrinsically low NRVS intensity, the $\mathrm{Fe}-\mathrm{D} / \mathrm{Fe}-\mathrm{CO}$ coupling allows for the high-intensity $\delta_{\mathrm{Fe}-\mathrm{CO}}$ region to serve as an indicator of whether or not a Fe-D moiety is present ${ }^{33}$.

DFT of model complexes. DFT calculations were undertaken to better understand the dynamics of H/D-coupled motions in the model complexes. The DFT-simulated ${ }^{57} \mathrm{Fe}$ PVDOS of $\left[\mathbf{1}^{\prime} \mathrm{H} / \mathrm{D}\right]^{+}$ $\mathrm{Ni} / \mathrm{Fe}$-flippamers were compared with NRVS data over the range $0-1,600 \mathrm{~cm}^{-1}$ (Fig. 2c, see also Supplementary Fig. 18 and Supplementary Tables 1 and 2). As with our recently reported spectra for $\left[\mathbf{1}^{\prime}\right]^{0 /+}$ (ref. 52), the observed and calculated band positions and intensities are in good agreement below $700 \mathrm{~cm}^{-1}$. 
Given that the broad $>700 \mathrm{~cm}^{-1}$ region is solely populated by $\mathrm{Ni} / \mathrm{Fe}-\mathrm{H} / \mathrm{D}$ bands, DFT also allows for a confident assignment of these NRVS features (Fig. 2b,c) despite their low intensities and the difficulties recognized in the accurate theoretical prediction of $\mathrm{M}-\mathrm{H}$ vibrational frequencies ${ }^{46}$.

In line with previous DFT calculations and Raman analyses ${ }^{46}$, the key distinction between calculated NRVS data for the two $\left[\mathbf{1}^{\prime} \mathrm{H}\right]^{+} \mathrm{Ni} / \mathrm{Fe}$-flippamers results from splitting of the $v_{\mathrm{Fe}-\mathrm{H}}=1,479 / 1,447 \mathrm{~cm}^{-1}$ and $v_{\mathrm{Ni}-\mathrm{H}}=1,022 / 1,061 \mathrm{~cm}^{-1}$ modes, respectively, as indicated in Fig. $2 c$. For the Ni-flippamer, the calculated $v_{\mathrm{Fe} / \mathrm{Ni}-\mathrm{H}}$ modes are shown correspondingly in Fig. $2 \mathrm{f}$,e and Supplementary Movies 1 and 2. As expounded in the 'Further Discussion on Model Complex' section of the Supplementary Discussion, a fine yet noticeable interplay of the optimized Ni/Fe$\mathrm{H}$ distances (Supplementary Table 3 ) gives rise to the inverted character of these $\sim 30-40 \mathrm{~cm}^{-1}$ flippamer-dependent splittings.

One of the most interesting and useful results from the present calculations on $\left[\mathbf{1}^{\prime} \mathrm{H}\right]^{+}$is the prediction of a ${ }^{57} \mathrm{Fe}$ PVDOS band at $774 / 767 \mathrm{~cm}^{-1}$ for the $\mathrm{Ni} / \mathrm{Fe}$-flippamers, respectively. With only a small flippamer-dependent splitting of $7 \mathrm{~cm}^{-1}$, this mode gives rise to the most intense feature above $700 \mathrm{~cm}^{-1}$ and aligns well with the NRVS band observed at $758 \mathrm{~cm}^{-1}$ (Fig. 2b,c). Inspection of the DFT-calculated nuclear displacements (see Fig. 2d and Supplementary Movie 3 for the mode animation) shows a $\mathrm{H}$ nucleus motion normal to the $\mathrm{Ni}(\mu-\mathrm{H}) \mathrm{Fe}$ plane, in what is a unique 'wagging' mode. While the $\mathrm{Ni}-\mathrm{H}-\mathrm{Fe}$ wag is relatively isolated in $\left[\mathbf{1}^{\prime} \mathrm{H}\right]^{+}(\mathrm{H}$ motion accounts for $\sim 80 \%$ of the kinetic energy), the corresponding Ni-D-Fe motion in $\left[\mathbf{1}^{\prime} \mathrm{D}\right]^{+}$ is predicted to be heavily mixed with $\mathrm{Fe}-\mathrm{CO}$ modes (Supplementary Table 1). The results of such mixing are evident in the intense $440-630 \mathrm{~cm}^{-1} \mathrm{Fe}-\mathrm{CO}$ region (Fig. $2 \mathrm{~b}, \mathrm{c}$ ). Thus, the NRVS signatures of the $\mathrm{Ni}-\mathrm{H}-\mathrm{Fe}$ moiety in the enzyme mimic are the weak wag band observed for $\left[\mathbf{1}^{\prime} \mathrm{H}\right]^{+}$and the change in the amplified features in the $\mathrm{Fe}-\mathrm{CO}$ region when comparing spectra of $\left[\mathbf{1}^{\prime} \mathrm{H}\right]^{+}$and $\left[\mathbf{1}^{\prime} \mathrm{D}\right]^{+}$.

Hydrogenase NRVS results. NRVS data for Ni-R in $\mathrm{H}_{2} / \mathrm{H}_{2} \mathrm{O}$ and in $\mathrm{D}_{2} / \mathrm{D}_{2} \mathrm{O}$ are compared in Fig. 3a. While vibrations of the three electron transport $\mathrm{Fe}-\mathrm{S}$ clusters exclusively populate the $<420 \mathrm{~cm}^{-1}$ region $^{39,40,43}$, this work instead focuses on the $\mathrm{Fe}-\mathrm{CO} / \mathrm{CN}$ region and higher-energy NRVS features to assign spectroscopic markers characteristic of the bridging hydride. Analysis of $\mathrm{Ni}-\mathrm{R}$ in $\mathrm{H}_{2} \mathrm{O}$ revealed a sharp band at $549 \mathrm{~cm}^{-1}$ previously assigned to a $v_{\mathrm{Fe}-\mathrm{CO}}$ mode ${ }^{39}$, with additional features at 454, 475 and $502 \mathrm{~cm}^{-1}$ arising from a mixture of $\mathrm{Fe}-\mathrm{CO}$ and $\mathrm{Fe}-\mathrm{CN}$ modes. Compared with our previous results ${ }^{39}$, the absence of shoulders and additional features around the $v_{\mathrm{Fe}-\mathrm{CO}}$ band indicates a higher level of sample purity. The NRVS band positions are similar to but nevertheless distinct from Raman peaks for the $\mathrm{Ni}-\mathrm{L} \mathrm{Ni} \mathrm{N}$ ) $\mathrm{Fe}(\mathrm{II})$ state of $[\mathrm{NiFe}]$-hydrogenase, for which $v_{\mathrm{Fe}-\mathrm{CO}}$ was observed at $559 \mathrm{~cm}^{-1}$ (ref. 53). Samples of Ni$\mathrm{R}$ in $\mathrm{H}_{2} \mathrm{O}$ exhibit bands at 590 and $609 \mathrm{~cm}^{-1}$ that collapse to a single peak at $609 \mathrm{~cm}^{-1}$ when $\mathrm{D}_{2} \mathrm{O}$ is instead used. Qualitatively, one can attribute the differences in this $\mathrm{Fe}-\mathrm{CO} / \mathrm{CN}$ region to a different coupling to $\mathrm{Fe}-\mathrm{H}$ and $\mathrm{Fe}-\mathrm{D}$ motion in the respective samples, as discussed above for $\left[\mathbf{1}^{\prime} \mathrm{H} / \mathrm{D}\right]^{+}$. Other details about the active site, such as whether cysteine ligands are unprotonated or protonated, cannot be addressed on the basis of the NRVS data alone.

NRVS analysis of [NiFe]-hydrogenase in $\mathrm{H}_{2} \mathrm{O}$ also revealed a weak but well-resolved band at $675 \mathrm{~cm}^{-1}$ not observed for other samples. This band is presumably related to the $\mathrm{Ni}-\mathrm{H}-\mathrm{Fe}$ wag exposed for $\left[\mathbf{1}^{\prime} \mathrm{H}\right]^{+}$at $758 \mathrm{~cm}^{-1}$ (Fig. 2b,d), making this the first assignment of a Fe-H-related mode in any enzyme by NRVS and the first direct spectroscopic evidence for a $\mathrm{Ni}(\mu-\mathrm{H}) \mathrm{Fe}$ core in
Ni-R. Deuteration of Ni-R is expected to red-shift this mode into the $420-620 \mathrm{~cm}^{-1} \mathrm{Fe}-\mathrm{CO} / \mathrm{CN}$ region, in agreement with the changes observed and calculated for $\left[\mathbf{1}^{\prime} \mathrm{D}\right]^{+}$. Analogous to the model complex, the Ni-D-Fe wag is strongly mixed with $\mathrm{Fe}-\mathrm{CO} /$ $\mathrm{CN}$ modes, which, in the case of $\mathrm{Ni}-\mathrm{R}$, makes its unique assignment very difficult.

Hydrogenase DFT results. To interpret NRVS measurements in terms of suitable structural candidates for $\mathrm{Ni}-\mathrm{R}$, we performed DFT calculations on a series of active site models featuring different binding modes of the $\mathrm{H}_{2}$ substrate or its heterolysis products (see Supplementary Fig. 19). Limiting our models to the [NiFe] site is appropriate in that $\mathrm{Fe}-\mathrm{S}$ clusters do not feature NRVS bands in the $>420 \mathrm{~cm}^{-1}$ region of interest ${ }^{39,40}$. Two main structures were considered: one in which substrate is present in the form of a dihydrogen ligand $\left(\left(\eta^{2}-\mathrm{H}_{2}\right) \mathrm{NiFe}, \mathbf{I}\right.$ or $\mathrm{NiFe}\left(\eta^{2}-\mathrm{H}_{2}\right)$, II) and another where a bridging hydride is present $(\mathrm{Ni}(\mu-\mathrm{H}) \mathrm{Fe}$, III or $\mathrm{HNi}(\mu-\mathrm{H}) \mathrm{Fe}, \mathbf{I V})$. In addition, variants of III, in which a terminal Cys ligand is protonated ((Cys546)SHNi $(\mu-\mathrm{H}) \mathrm{Fe}, \mathrm{V}$ and (Cys81)SHNi( $\mu$-H)Fe, VI), were also studied. Taking into account the $\mathrm{Ni}$ (II) $\mathrm{Fe}$ (II) $\mathrm{Ni}-\mathrm{R}$ active site ${ }^{16,18}$, and assuming $\mathrm{Fe}$ (II) remains low-spin, each model may exist in electronic singlet $(S=0)$ or triplet $(S=1) \mathrm{Ni}(\mathrm{II})$ states, both of which were evaluated computationally. The DFT-calculated ${ }^{57} \mathrm{Fe}$ PVDOS for selected models were compared with the NRVS data for Ni-R over the range $400-750 \mathrm{~cm}^{-1}$ (Fig. 3a-c, see 'Further Discussion of Enzyme Cluster Models' of the Supplementary Discussion and Supplementary Figs 20-30). DFT-calculated NRVS for models $\mathbf{V}^{\mathbf{S}}$ and $\mathbf{V I}^{\mathbf{S}}$ (Fig. 3d,e, superscript $\mathrm{S}$ denotes singlet $\mathrm{Ni}(\mathrm{II})$ ) match experimental data remarkably well, with the number and positions of absorption bands being in accordance. Relative intensities of the calculated peaks are also in good agreement with our measurements.

According to the normal mode analysis of model $\mathbf{V}^{\mathbf{S}}$ (Supplementary Figs 28 and 29; animated representations of vibrational modes for models $\mathbf{V}^{\mathbf{S}}$ and $\mathbf{V I}^{\mathbf{S}}$ are provided in Supplementary Movies 4-34), vibrations in the $440-504 \mathrm{~cm}^{-1}$ region predominantly involve $\mathrm{Fe}-\mathrm{CN}$ bending and stretching, while higher-energy bands $\left(543-613 \mathrm{~cm}^{-1}\right)$ are derived from $\mathrm{Fe}-\mathrm{CO}$ vibrations. The feature calculated at $543 \mathrm{~cm}^{-1}$ has significant $v_{\mathrm{Fe}-\mathrm{CO}}$ character, while that at $613 \mathrm{~cm}^{-1}$ is assigned to a $\delta_{\mathrm{Fe}-\mathrm{CO}}$ mode. Likewise, the $588 \mathrm{~cm}^{-1}$ band can be assigned to an $\mathrm{H}-\mathrm{Fe}-\mathrm{CO}$ bend in which $\mathrm{H}, \mathrm{Fe}$ and $\mathrm{C}$ remain nearly collinear. The above normal modes are highly mixed, which make the assignment of individual fragments complicated.

Both bridging hydride models $\mathbf{V}^{\mathbf{S}}$ and $\mathbf{V I}^{\mathbf{S}}$ are predicted to exhibit a weak Ni-H-Fe out-of-plane wagging band (at 727 and $692 \mathrm{~cm}^{-1}$, respectively, see Fig. 3; Supplementary Movies 11 and 28 for mode animations) whose intensity is comparable to that of the $675 \mathrm{~cm}^{-1}$ feature observed for Ni-R. When compared with the $\mathrm{Fe}-\mathrm{CO} / \mathrm{CN}$ region, both theory and experiment predict lower NRVS intensity of the wag in Ni-R than that observed and calculated for $\left[\mathbf{1}^{\prime} \mathrm{H}\right]^{+}$(at 758 and $774 / 767 \mathrm{~cm}^{-1}$, respectively, see Fig. 2). Moreover, simulations for $\mathbf{V}^{\mathbf{S}}$ and $\mathbf{V I}^{\mathbf{S}}$ accurately reproduce the disappearance of the $675 \mathrm{~cm}^{-1}$ band in data for $\mathrm{Ni}-\mathrm{R}$ in $\mathrm{D}_{2} \mathrm{O}$. The difference between the experimental and calculated frequencies of the wagging mode are likely due to limitations in our model, which does not take into account direct contacts between the protonated cysteines and surrounding residues, as well as anharmonicity effects. Moreover, one would expect an intrinsic error of the chosen functional/basis set combination. While hydride bands are extremely sensitive to (electronic) structure, we note that the observed error is still well within normal limits ${ }^{54-58}$ expected for this methodology. However, since the full spectral information is considered in 

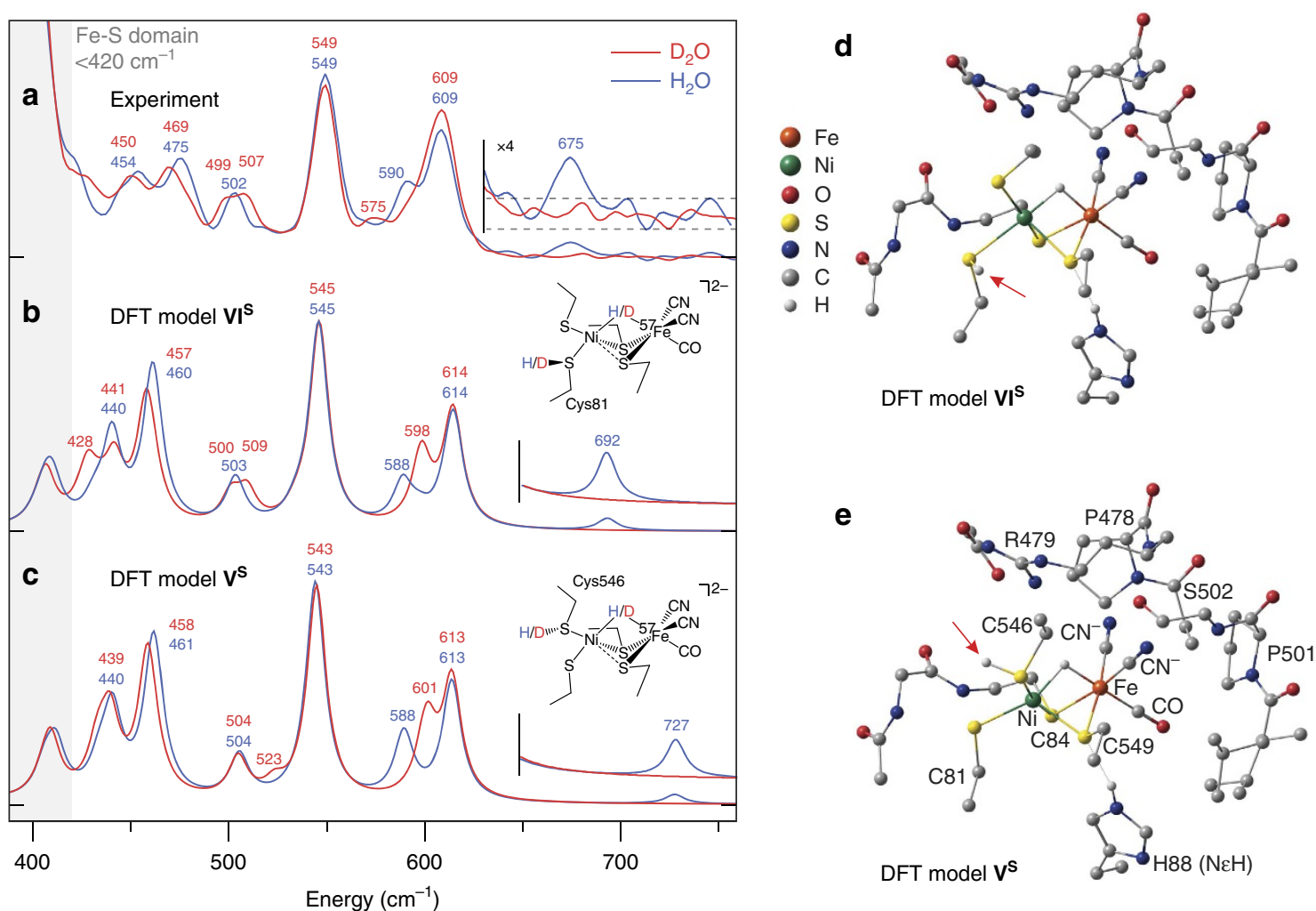

Figure 3 | Ni-H-Fe-hydride wag exposed in the reduced state Ni-R of [NiFe]-hydrogenase. (a-c) High-frequency NRVS for [NiFe]-hydrogenase reduced in $\mathrm{H}_{2} \mathrm{O}$ (blue trace) and $\mathrm{D}_{2} \mathrm{O}$ (red trace; a) and the corresponding ${ }^{57} \mathrm{Fe}$ PVDOS simulations given for the representative DFT models $\mathbf{V I} \mathbf{I}^{\mathbf{S}}$ (b) and $\mathbf{V}^{\mathbf{S}}$ (c). The higher regions of spectra containing the $\mathrm{Ni}-\mathrm{H}-\mathrm{Fe}$ wag band (in $\mathrm{H}_{2} \mathrm{O}$ samples) are repeated with their intensities $\times 4$ amplified. The low-energy region of the Ni-R spectrum in $\mathrm{H}_{2} \mathrm{O}$ reveals a triplet of bands $\left(454,475\right.$ and $502 \mathrm{~cm}^{-1}$ ) that correspond to those located at 440,461 and $504 \mathrm{~cm}^{-1}$ in the calculated spectrum of the model $\mathbf{V}^{\mathbf{S}}$. Further, two intense bands seen at 549 and $609 \mathrm{~cm}^{-1}$ in Ni-R map on calculated bands at 543 and $613 \mathrm{~cm}{ }^{-1}$, with an additional weak band observed at $590 \mathrm{~cm}^{-1}$ that can be correlated with the calculated band appearing at $588 \mathrm{~cm}^{-1}$. (d,e) Representative DFT-optimized models $\mathbf{V} \mathbf{I}^{\mathbf{S}}$ (d) and $\mathbf{V}^{\mathbf{S}}$ (e) for the Ni-R active site. Arrows indicate the position of Cys SH. Non-substrate $\mathrm{H}$ atoms have been omitted for clarity (excluding $\mathrm{HN} \varepsilon$ of His88).

the interpretation, the present conclusions can be made with confidence. Finally, calculated H/D isotope shifts for the two representative models (Supplementary Tables 4 and 5) in the lowenergy region are also fully consistent with the observed data. The overall analysis here identifies the $675 \mathrm{~cm}^{-1}$ feature in the Ni-R NRVS spectrum as the $\mathrm{Ni}-\mathrm{H}-\mathrm{Fe}$ wag mode.

\section{Discussion}

Our NRVS measurements on synthetic bridging hydrides and $\mathrm{Ni}-\mathrm{R}$, combined with DFT calculations, provide new constraints on the structure of this key catalytic state of [NiFe]-hydrogenase. Spectra of $\left[\mathbf{1}^{\prime} \mathrm{H} / \mathrm{D}\right]^{+}$feature characteristic Fe-H/D stretches whose energies $\left(1,532 / 1,468 \mathrm{~cm}^{-1}\right.$ for the $\mathrm{Ni} / \mathrm{Fe}$-flippamer, respectively) are comparable to those for bridging hydrides in other structures, including another recently reported $\mathrm{Ni}(\mu \text {-thiolate })_{2}(\mu-\mathrm{H}) \mathrm{Fe}$ species for which infrared spectroscopy revealed a $v_{\mathrm{Fe}-\mathrm{H}}$ band at $1,687 \mathrm{~cm}^{-1}$ (ref. 28). Symmetrical $\mu_{2}-\mathrm{H}^{-}$bridges, such as those in $\mathrm{Fe}_{4} \mathrm{H}_{4}^{+}$clusters, give rise to symmetric stretches at around $1,400 \mathrm{~cm}^{-1}$ (ref. 59), while purely terminal hydrides have $v_{\mathrm{Fe}-\mathrm{H}} \sim 1,700-2,300 \mathrm{~cm}^{-1}$ (refs 33,60 ). The sensitivity of hydride vibrations to structural perturbations underscores their enormous diagnostic value in understanding catalyst structure and function.

Unfortunately, even the strongest of these relatively pure stretches, $v_{\mathrm{Fe}-\mathrm{D}}$, is predicted to have much lower NRVS intensity than the $v_{\mathrm{Fe}-\mathrm{CO}}$ modes. Thus, while $\left[\mathbf{1}^{\prime} \mathrm{H} / \mathrm{D}\right]^{+}$allowed for direct observation of $v_{\mathrm{Fe}-\mathrm{H} / \mathrm{D}}$ and $v_{\mathrm{Ni}-\mathrm{H} / \mathrm{D}}$ modes, the resolution of similar bands for [NiFe]-hydrogenase is beyond our current capabilities.

Of special significance is the DFT prediction of a Ni-H-Fe wag (Fig. 2d), this vibration being assigned to an observed NRVS band at $758 \mathrm{~cm}^{-1}$ for $\left[\mathbf{1}^{\prime} \mathrm{H}\right]^{+}$, a mode likely obscured by solvent bands in Raman spectra ${ }^{46}$. A key advantage of NRVS is thus demonstrated in that its sole detection of modes coupled to the Mössbauer-active ${ }^{57} \mathrm{Fe}$ nucleus makes it unaffected by solvent or matrix modes. The NRVS intensity of the $\mathrm{Ni}-\mathrm{H}-\mathrm{Fe}$ wag is at least four times greater than those of the $\mathrm{Ni}-\mathrm{H} / \mathrm{Fe}-\mathrm{H}$ stretches. The $\mathrm{Ni}-\mathrm{H}-\mathrm{Fe}$ wag is a valuable diagnostic probe of the Ni-R structure, with NRVS data for $\mathrm{Ni}-\mathrm{R}$ in $\mathrm{H}_{2} \mathrm{O}$ featuring a weak but reproducible band at $675 \mathrm{~cm}^{-1}$ that is absent when a $\mathrm{D}_{2} \mathrm{O}$ medium was used (Fig. 3). Given that ${ }^{57} \mathrm{Fe}$ NRVS-active modes necessarily involve motion of this metal centre, observation of an $\mathrm{H} / \mathrm{D}$ isotopically sensitive band at $675 \mathrm{~cm}^{-1}$ is strong evidence for the presence of a $\mathrm{Fe}-\mathrm{H}$ moiety in Ni-R.

A second observable indicating the presence of a bridging $\mathrm{H}^{-} / \mathrm{D}^{-}$in both $\mathrm{Ni}-\mathrm{R}$ and its mimics $\left[\mathbf{1}^{\prime} \mathrm{H} / \mathrm{D}\right]^{+}$stems from the coupling of $\mathrm{Fe}-\mathrm{CO}$ and $\mathrm{Fe}-\mathrm{CN}$ stretches and bends with the $\mathrm{Ni}-\mathrm{D}-\mathrm{Fe}$ wag. While coupling to the $\mathrm{Fe}-\mathrm{CO} / \mathrm{CN}$ modes makes resolution of the $\mathrm{Ni}-\mathrm{D}-\mathrm{Fe}$ wag impossible, it also results in marked changes in band position and intensity in the $440-630 \mathrm{~cm}^{-1}$ region on $\mathrm{H} / \mathrm{D}$ substitution (Figs 2 and 3 ). In line with the marked isotope effects described above for $\left[\mathbf{1}^{\prime} \mathrm{H} / \mathrm{D}\right]^{+}$, NRVS spectra of $\mathrm{Ni}-\mathrm{R}$ display similar shifts in position and intensity around $450-480 \mathrm{~cm}^{-1}$, splitting of a band at $502 \mathrm{~cm}^{-1}$, and 
disappearance of a shoulder peak at $590 \mathrm{~cm}^{-1}$. This coupling provides an indirect but powerful method for characterizing the Fe-H/D-binding geometry. The NRVS experiments were complemented by DFT simulations, which further pointed to the presence of an active-site bridging hydride. Spectra predicted for the singlet $(S=0)$ models (Cys81)SHNi $(\mu-\mathrm{H}) \mathrm{Fe} \quad\left(\mathbf{V I}^{\mathbf{S}}\right)$ and (Cys546)SHNi $(\mu-\mathrm{H}) \mathrm{Fe}\left(\mathbf{V}^{\mathbf{S}}\right)$ reproduce the data exceptionally well, in particular with respect to the Ni-H-Fe wag in each H/D isotopologue. The model $\mathbf{V}^{\mathbf{S}}$ is also supported by the recent highresolution crystallographic analysis of Ni-R1 (ref. 27). As detailed in the 'Further Discussion of Enzyme Cluster Models' section of the Supplementary Discussion, the NRVS data are best reproduced assuming a low-spin Ni(II). DFT also indicated asymmetric binding of $\mathrm{H}^{-}$to the $\mathrm{Ni}(\mathrm{II}) \mathrm{Fe}$ (II) core, with the ligand more strongly bound to $\mathrm{Ni}$ than to $\mathrm{Fe}$ (see 'Electronic Structure of Model V' of the Supplementary Discussion).

Taken together, NRVS analysis of $\mathrm{Ni}-\mathrm{R}$, in combination with NRVS and DFT data for $\left[\mathbf{1}^{\prime} \mathrm{H} / \mathrm{D}\right]^{+}$, indicates that models $\mathrm{VI}^{\mathrm{S}}$ and $\mathrm{V}^{\mathrm{S}}$ provide a consistent and detailed picture of Ni-R. This cohesive study thus represents the first evidence from vibrational spectroscopy for the presence of a bridging $\mathrm{H}^{-}$in the active site of Ni-R, a state central to the function of [NiFe]-hydrogenase. The combined experimental and theoretical approach described here has applicability far beyond the $\mathrm{Ni}-\mathrm{R}$ and [NiFe]hydrogenase. Ideal for the detailed study of $\mathrm{Fe}-\mathrm{H}$ fragments, we envisage that such methods will also be of importance for unravelling the mechanisms of [FeFe]-hydrogenase and nitrogenase $^{61}$, as well as for the development of synthetic catalysts inspired by these metalloenzymes.

\section{Methods}

General. Protocols employed for chemical and biochemical synthesis, as well as NRVS measurements and DFT calculations, are outlined here. Full procedures, including associated references, are given in the Supplementary Methods.

Model complex preparation. Metallic ${ }^{57} \mathrm{Fe}$ was converted to the complex (dppe) $\mathrm{Ni}(\mu \text {-pdt })^{57} \mathrm{Fe}(\mathrm{CO})_{3}\left(\mathbf{1}^{\prime}\right)$ via the intermediates ${ }^{57} \mathrm{Fe}_{2} \mathrm{I}_{4}(2 \text {-propanol })_{4}$, (dppe) $\mathrm{Ni}(\mu \text {-pdt })^{57} \mathrm{FeI}_{2}$ and $\left[(\mathrm{dppe}) \mathrm{Ni}\left(\mu\right.\right.$-pdt) $\left(\mu\right.$-I I $\left.{ }^{57} \mathrm{Fe}(\mathrm{CO})_{3}\right] \mathrm{BF}_{4}\left(\left[\mathbf{1}^{\prime} \mathrm{I}\right] \mathrm{BF}_{4}\right)$ (ref. 52). Species $\mathbf{1}^{\prime}$ underwent facile exchange with ${ }^{13} \mathrm{CO}(1 \mathrm{~atm})$, allowing access to isotopologue (dppe) $\mathrm{Ni}(\mu \text {-pdt })^{57} \mathrm{Fe}\left({ }^{13} \mathrm{CO}\right)_{3}\left(\mathbf{1}^{\prime \prime}\right)$. The two $\mathrm{Ni}(\mathrm{I}) \mathrm{Fe}(\mathrm{I})$ derivatives $\mathbf{1}^{\prime}$ and $\mathbf{1}^{\prime \prime}$ were then subjected to protonation and deuteronation (effected with excess $\mathrm{HBF}_{4}$ and $\mathrm{HBF}_{4} / \mathrm{CD}_{3} \mathrm{OD}$, respectively), affording the $\mathrm{Ni}(\mathrm{II}) \mathrm{Fe}(\mathrm{II})$ salts $\left[\mathbf{1}^{\prime} \mathrm{H}\right] \mathrm{BF}_{4}$, $\left[\mathbf{1}^{\prime} \mathrm{D}\right] \mathrm{BF}_{4},\left[\mathbf{1}^{\prime} \mathrm{H}\right] \mathrm{BF}_{4}$ and $\left[\mathbf{1}^{\prime \prime} \mathrm{D}\right] \mathrm{BF}_{4}$ as crystalline solids. The isotopic purity of the hydrides and deuterides was confirmed using multinuclear $\left({ }^{1} \mathrm{H},{ }^{2} \mathrm{H},{ }^{13} \mathrm{C}\right.$ and $\left.{ }^{31} \mathrm{P}\right)$ NMR spectroscopy, infrared spectroscopy and ESI mass spectrometry. NRVS analysis was conducted on a solid sample of each of the four model complexes (vide infra).

D. vulgaris Miyazaki F [NiFe]-hydrogenase preparation. [NiFe]-hydrogenase expressed in D. vulgaris was isolated and purified as described earlier ${ }^{62}$. The as-isolated protein was transferred from $25 \mathrm{mM}$ Tris- $\mathrm{HCl}(\mathrm{pH}=7.4)$ buffer to $100 \mathrm{mM}$ MES $(\mathrm{pH}=5.0)$. The solution was placed in a tube, which was sealed, degassed and then purged with $\mathrm{H}_{2}(1.2 \mathrm{bar})$ for $8 \mathrm{~h}$. In the case of the sample in $\mathrm{D}_{2} \mathrm{O}$, the buffer was replaced by $100 \mathrm{mM}$ MES $(\mathrm{pD}=5.0)$ in $\mathrm{D}_{2} \mathrm{O}$ and the mixture placed under $\mathrm{D}_{2}(1.3 \mathrm{bar})$ for $8 \mathrm{~h}$. Samples were transferred to an anaerobic chamber and loaded into NRVS cells. FT-IR spectra were recorded on a Bruker IFS66v/S FT-IR spectrometer with a $2 \mathrm{~cm}^{-1}$ spectral resolution at $293 \mathrm{~K}$ (Supplementary Fig. 31).

NRVS measurements and data analysis. The NRVS data were collected according to a published procedure ${ }^{39}$ at SPring-8 BL09XU (with flux $\sim 1.4 \times 10^{9}$ photons $\left.\mathrm{s}^{-1}\right)$ and BL19LXU $\left(\sim 6 \times 10^{9}\right.$ photons $\left.^{-1}\right)$ using $14.4 \mathrm{keV}$ radiation at $0.8 \mathrm{meV}$ resolution. The spectral maximum counts/second (cts s${ }^{-1}$ ) at BL19 is $\sim 2.6-3$ times of that at BL09. To compare the data from different beamlines, we rescale the BL19 counting time on the basis of its $\max$ cts s $^{-1}$ versus the max $\mathrm{cts} \mathrm{s}^{-1}$ at BL09 and create BL09 equivalent seconds, for example, the 10 (s) per point (s/pt) at BL19 is corresponding to 26 or 30 equivalent $s / p t$ at BL09. Delayed nuclear and $\mathrm{Fe} \mathrm{K}$ fluorescence (from internal conversion) were recorded with a $2 \times 2$ APD (avalanche photodiode) array in either beamline, and raw NRVS data were converted to single-phonon ${ }^{57} \mathrm{Fe}$ PVDOS using the PHOENIX software ${ }^{39}$. Sample temperatures were maintained at $30-50 \mathrm{~K}$ during analysis.
The average cts $\mathrm{s}^{-1}$ is $0.6-0.8$ at the Fe-CO peak $\left(609 \mathrm{~cm}^{-1}\right)$ and $0.10-0.12$ at $\mathrm{X}-\mathrm{Fe}-\mathrm{H}$ peak $\left(675 \mathrm{~cm}^{-1}\right)$, while the measured dark background cts are $\sim 0.03$ $\mathrm{cts} \mathrm{s}^{-1}$. To improve weak features, we use $1-3 \mathrm{~s} / \mathrm{pt}$ from -240 to $400 \mathrm{~cm}^{-1}$, $5-10 \mathrm{~s} / \mathrm{pt}$ for the $\mathrm{Fe}-\mathrm{CN}$ and $\mathrm{Fe}-\mathrm{CO}$ regions, and $10-30 \mathrm{~s} / \mathrm{pt}$ for the candidate $\mathrm{X}-\mathrm{Fe}-\mathrm{H}$ bending region $\left(\right.$ at $620-770 \mathrm{~cm}^{-1}$ ).

Model complex calculations. Initial coordinates for the DFT calculations on $\left[\mathbf{1}^{\prime} \mathrm{H} / \mathrm{D}\right]^{+}$were extracted from the X-ray structure of $[1 \mathrm{H}] \mathrm{BF}_{4} \cdot 3 \mathrm{THF}$ (ref. 44 ). The methodology applied was mostly equivalent to our earlier set-up on $\left[\mathbf{1}^{\prime}\right]^{0 /+}$ (ref. 52). Structural optimizations and subsequent normal mode analyses were performed using GAUSSIAN 09 on the basis of the densities exported from single point calculations using JAGUAR 7.9. The BP86 functional and the LACV3P** basis set were employed. The environment was considered using a self-consistent reaction field model. ${ }^{57} \mathrm{Fe}$ PVDOS spectra were generated using Q-SPECTOR, successfully applied earlier ${ }^{33}$. Simulated spectra were broadened by convolution with a full-width at half-maximum $=12 \mathrm{~cm}^{-1}$ Lorentzian.

Enzyme cluster model calculations. DFT calculations on active-site cluster models were performed using ORCA 3.0. The initial geometry was prepared from the crystal structure of reduced [NiFe]-hydrogenase from Desulfovibrio vulgaris Miyazaki F $(\mathrm{PDB} 1 \mathrm{H} 2 \mathrm{R})^{63}$. Constraint geometry optimizations and vibrational frequency calculations at the scalar relativistic level (ZORA) employed B3LYP(-D3) hybridGGA with RIJCOSx and the COSMO model $(\varepsilon=4)$. Segmented all-electron relativistically contracted basis sets with corresponding auxiliary basis sets were used (def2-TZVPP: $\mathrm{Ni}, \mathrm{Fe}, \mathrm{CN}^{-}, \mathrm{CO}, \mathrm{S} \gamma, \mathrm{H}^{-}, \mathrm{H}^{+}, \mathrm{H}_{2}$; def2-SV(P): remaining atoms). Vibrational frequencies and normal mode compositions were utilized to simulate NRVS data (Lorentzian fitting, linewidth $12 \mathrm{~cm}^{-1}$ ).

\section{References}

1. Bockris, J. O. M. The hydrogen economy: its history. Int. J. Hydrogen Energy 38, 2579-2588 (2013).

2. Jugder, B. E., Welch, J., Aguey-Zinsou, K. F. \& Marquis, C. P. Fundamentals and electrochemical applications of Ni-Fe uptake hydrogenases. RSC Adv. 3, 8142-8159 (2013).

3. Kim, J. Y. H. \& Cha, H. J. Recent progress in hydrogenase and its biotechnological application for viable hydrogen technology. Korean J. Chem. Eng. 30, 1-10 (2013).

4. Mertens, R. \& Liese, A. Biotechnological applications of hydrogenases. Curr. Opin. Biotechnol. 15, 343-348 (2004).

5. Cammack, R., Frey, M. \& Robson, R. (Eds.) Hydrogen as a Fuel: Learning from Nature (Taylor \& Francis, 2001).

6. Heinekey, D. M. Hydrogenase enzymes: recent structural studies and active site models. J. Organomet. Chem. 694, 2671-2680 (2009).

7. Tard, C. \& Pickett, C. J. Structural and functional analogues of the active sites of the [Fe]-, [NiFe]-, and [FeFe]-hydrogenases. Chem. Rev. 109, 2245-2274 (2009).

8. Yang, J. Y., Bullock, M., Rakowski DuBois, M. \& DuBois, D. L. Fast and efficient molecular electrocatalysts for $\mathrm{H}_{2}$ production: Using hydrogenase enzymes as guides. MRS Bull. 36, 39-47 (2011).

9. Fritsch, J., Lenz, O. \& Friedrich, B. Structure, function and biosynthesis of $\mathrm{O}_{2}$-tolerant hydrogenases. Nat. Rev. Microbiol. 11, 106-114 (2013).

10. Simmons, T. R. \& Artero, V. Catalytic hydrogen oxidation: Dawn of a new iron age. Angew. Chem. Int. Ed. 52, 6143-6145 (2013).

11. Matsumoto, T., Kim, K., Nakai, H., Hibino, T. \& Ogo, S. Organometallic catalysts for use in a fuel cell. ChemCatChem 5, 1368-1373 (2013).

12. Evans, R. M. et al. Principles of sustained enzymatic hydrogen oxidation in the presence of oxygen - the crucial influence of high potential Fe-S clusters in the electron relay of [NiFe]-hydrogenases. J. Am. Chem. Soc. 135, 2694-2707 (2013).

13. Armstrong, F. A. Dynamic electrochemical experiments on hydrogenases. Photosynth. Res. 102, 541-550 (2009).

14. Shafaat, H. S., Rüdiger, O., Ogata, H. \& Lubitz, W. [NiFe] hydrogenases: a common active site for hydrogen metabolism under diverse conditions. Biochim. Biophys. Acta 1827, 986-1002 (2013).

15. Guiral, M. et al. Hyperthermostable and oxygen resistant hydrogenases from a hyperthermophilic bacterium Aquifex aeolicus: physicochemical properties. Int. J. Hydrogen Energy 31, 1424-1431 (2006).

16. Lubitz, W., Ogata, H., Rüdiger, O. \& Reijerse, E. Hydrogenases. Chem. Rev. 114, 4081-4148 (2014).

17. Ogata, H., Lubitz, W. \& Higuchi, Y. [NiFe] hydrogenases: structural and spectroscopic studies of the reaction mechanism. Dalton Trans. 7577-7587 (2009).

18. Pandelia, M.-E., Ogata, H. \& Lubitz, W. Intermediates in the catalytic cycle of [NiFe] hydrogenase: functional spectroscopy of the active site. ChemPhysChem 11, 1127-1140 (2010).

19. Dole, F. et al. Nature and electronic structure of the Ni-X dinuclear center of Desulfovibrio gigas hydrogenase. Implications for the enzymatic mechanism. Biochemistry 36, 7847-7854 (1997). 
20. Bruschi, M. et al. A theoretical study of spin states in $\mathrm{Ni}-\mathrm{S}_{4}$ complexes and models of the [NiFe] hydrogenase active site. J. Biol. Inorg. Chem. 9, 873-884 (2004).

21. Lill, S. O. N. \& Siegbahn, P. E. M. An autocatalytic mechanism for NiFehydrogenase: reduction to $\mathrm{Ni}(\mathrm{I})$ followed by oxidative addition. Biochemistry 48, 1056-1066 (2009).

22. Zampella, G., Bruschi, M., Fantucci, P. \& De Gioia, L. DFT investigation of $\mathrm{H}_{2}$ activation by $\left[\mathrm{M}\left(\mathrm{NHP} n \mathrm{Pr}_{3}\right)\left({ }^{\prime} \mathrm{S} 3\right.\right.$ ') $\left.)\right](\mathrm{M}=\mathrm{Ni}, \mathrm{Pd})$. Insight into key factors relevant to the design of hydrogenase functional models. J. Am. Chem. Soc. 127, 13180-13189 (2005).

23. Amara, P., Volbeda, A., Fontecilla-Camps, J. C. \& Field, M. J. A hybrid density functional theory/molecular mechanics study of nickel-iron hydrogenase: investigation of the active site redox states. J. Am. Chem. Soc. 121, 4468-4477 (1999).

24. Stein, M. \& Lubitz, W. Relativistic DFT calculation of the reaction cycle intermediates of [NiFe] hydrogenase: a contribution to understanding the enzymatic mechanism. J. Inorg. Biochem. 98, 862-877 (2004).

25. Siegbahn, P. E. M., Blomberg, M. R. A., Pavlov, M. W. N. \& Crabtree, R. H. The mechanism of the Ni-Fe hydrogenases: a quantum chemical perspective. J. Biol. Inorg. Chem. 6, 460-466 (2001).

26. Niu, S., Thomson, L. M. \& Hall, M. B. Theoretical characterization of the reaction intermediates in a model of the nickel-iron hydrogenase of Desulfovibrio gigas. J. Am. Chem. Soc. 121, 4000-4007 (1999).

27. Ogata, H., Nishikawa, K. \& Lubitz, W. Hydrogens detected by subatomic resolution protein crystallography in a $[\mathrm{NiFe}]$ hydrogenase. Nature 520, 571-574 (2015).

28. Ogo, S. et al. A functional [NiFe] hydrogenase mimic that catalyzes electron and hydride transfer from $\mathrm{H}_{2}$. Science 339, 682-684 (2013).

29. Fan, H. J. \& Hall, M. B. High-spin Ni(II), a surprisingly good structural model for [NiFe] hydrogenase. J. Am. Chem. Soc. 124, 394-395 (2002).

30. Jayapal, P., Robinson, D., Sundararajan, M., Hillier, I. H. \& McDouall, J. J. W. High level $a b$ initio and DFT calculations of models of the catalytically active Ni-Fe hydrogenases. Phys. Chem. Chem. Phys. 10, 1734-1738 (2008).

31. Bruschi, M., Zampella, G., Fantucci, P. \& De Gioia, L. DFT investigations of models related to the active site of $[\mathrm{NiFe}]$ and $[\mathrm{Fe}]$ hydrogenases. Coord. Chem. Rev. 249, 1620-1640 (2005).

32. Yson, R. L., Gilgor, J. L., Guberman, B. A. \& Varganov, S. A. Protein induced singlet-triplet quasidegeneracy in the active site of [NiFe]-hydrogenase. Chem. Phys. Lett. 577, 138-141 (2013).

33. Pelmenschikov, V., Guo, Y., Wang, H., Cramer, S. P. \& Case, D. A. Fe-H/D stretching and bending modes in nuclear resonant vibrational, Raman and infrared spectroscopies: comparisons of density functional theory and experiment. Faraday Discuss. 148, 409-420 (2011).

34. Champeney, D. C. The scattering of Mössbauer radiation by condensed matter. J. Rep. Prog. Phys. 42, 1017-1054 (1979).

35. Seto, M., Yoda, Y., Kikuta, S., Zhang, X. W. \& Ando, M. Observation of nuclear resonant scattering accompanied by phonon excitation using synchrotron radiation. Phys. Rev. Lett. 74, 3828-2831 (1995).

36. Alp, E. E. et al. Vibrational dynamics studies by nuclear resonant inelastic X-ray scattering. Hyperfine Interact. 144/145, 3-20 (2002).

37. Sturhahn, W. Nuclear resonant spectroscopy. J. Phys. Condens. Matter 16, S497-S530 (2004).

38. Sturhahn, W. et al. Phonon density of states measured by inelastic nuclear resonant scattering. Phys. Rev. Lett. 74, 3832-3835 (1995).

39. Kamali, S. et al. Observation of the Fe-CN and Fe-CO vibrations in the active site of $[\mathrm{NiFe}]$ hydrogenase by nuclear resonance vibrational spectroscopy. Angew. Chem. Int. Ed. 52, 724-728 (2013).

40. Lauterbach, L. et al. Nuclear resonance vibrational spectroscopy reveals the FeS cluster composition and active site vibrational properties of an $\mathrm{O}_{2}$-tolerant $\mathrm{NAD}(+)$-reducing $[\mathrm{NiFe}]$ hydrogenase. Chem. Sci. 6, 1055-1060 (2015).

41. Xiao, Y. et al. Dynamics of Rhodobacter capsulatus [2Fe-2S] ferredoxin VI and Aquifex aeolicus ferredoxin 5 via nuclear resonance vibrational spectroscopy (NRVS) and resonance raman spectroscopy. Biochemistry 47, 6612-6627 (2008).

42. Mitra, D. et al. Dynamics of the [4Fe-4S] cluster in Pyrococcus furiosus D14C ferredoxin via nuclear resonance vibrational and resonance raman spectroscopies, force field simulations, and density functional theory calculations. Biochemistry 50, 5220-5235 (2011).

43. Mitra, D. et al. Characterization of [4Fe-4S] cluster dynamics and structure in nitrogenase Fe Protein at three oxidation levels via combined NRVS, EXAFS and DFT analyses. J. Am. Chem. Soc. 135, 2530-2543 (2013).

44. Barton, B. E., Whaley, C. M., Rauchfuss, T. B. \& Gray, D. L. Nickel-iron dithiolato hydrides relevant to the [NiFe]-hydrogenase active site. J. Am. Chem. Soc. 131, 6942-6943 (2009).

45. Barton, B. E. \& Rauchfuss, T. B. Hydride-containing models for the active site of the nickel-iron hydrogenases. J. Am. Chem. Soc. 132, 14877-14885 (2010).

46. Shafaat, H. S., Weber, K., Petrenko, T., Neese, F. \& Lubitz, W. Key hydride vibrational modes in $[\mathrm{NiFe}]$ hydrogenase model compounds studied by resonance Raman spectroscopy and density functional calculations. Inorg. Chem. 51, 11787-11797 (2012).

47. Bertini, L., Greco, C., Bruschi, M., Fantucci, P. \& De Gioia, L. CO affinity and bonding properties of [FeFe] hydrogenase active site models. A DFT study. Organometallics 29, 2013-2025 (2010).

48. Liu, T. B., Li, B., Singleton, M. L., Hall, M. B. \& Darensbourg, M. Y. Sulfur oxygenates of biomimetics of the diiron subsite of the [FeFe]-hydrogenase active site: Properties and oxygen damage repair possibilities. J. Am. Chem. Soc. 131, 8296-8307 (2009).

49. Schilter, D. et al. Mixed-valence nickel-iron dithiolate models of the [NiFe]hydrogenase active site. Inorg. Chem. 51, 2338-2348 (2012).

50. Justice, A. K. et al. Redox and structural properties of mixed-valence models for the active site of the [FeFe]-hydrogenase: progress and challenges. Inorg. Chem. 47, 7405-7414 (2008).

51. Bergmann, U. et al. Observation of Fe-H/D modes by nuclear resonant vibrational spectroscopy. J. Am. Chem. Soc. 125, 4016-4017 (2003).

52. Schilter, D. et al. Synthesis and vibrational spectroscopy of ${ }^{57} \mathrm{Fe}$-labeled models of [NiFe] hydrogenase: first direct observation of a nickel-iron interaction. Chem. Commun. 50, 13469-13472 (2014).

53. Siebert, E. et al. Resonance Raman spectroscopy as a tool to monitor the active site of hydrogenases. Angew. Chem. Int. Ed. 52, 5162-5165 (2013).

54. Petrenko, T. et al. Characterization of a genuine iron(V)-nitrido species by nuclear resonant vibrational spectroscopy coupled to density functional calculations. J. Am. Chem. Soc. 129, 11053-11060 (2007).

55. Peng, Q., Pavlik, J. W., Scheidt, W. R. \& Wiest, O. Predicting nuclear resonance vibrational spectra of $[\mathrm{Fe}(\mathrm{OEP})(\mathrm{NO})]$. J. Chem. Theory Comput. 8, 214-223 (2012).

56. Wong, S. D. et al. Elucidation of the $\mathrm{Fe}(\mathrm{IV})=\mathrm{O}$ intermediate in the catalytic cycle of the halogenase SyrB2. Nature 499, 320-323 (2013).

57. Park, K. et al. Nuclear resonance vibrational spectroscopic and computational study of high-valent diiron complexes relevant to enzyme intermediates. Proc. Natl Acad. Sci. USA 110, 6275-6280 (2013).

58. Li, J. F. et al. Comprehensive Fe-ligand vibration identification in $\{\mathrm{FeNO}\}^{6}$ hemes. J. Am. Chem. Soc. 136, 18100-18110 (2014).

59. Swart, I. et al. $\mathrm{H}_{2}$ adsorption on $3 \mathrm{~d}$ transition metal clusters: a combined infrared spectroscopy and density functional study. J. Phys. Chem. A 112, 1139-1149 (2008).

60. Kubas, G. J. Fundamentals of $\mathrm{H}_{2}$ binding and reactivity on transition metals underlying hydrogenase function and $\mathrm{H}_{2}$ production and storage. Chem. Rev. 107, 4152-4205 (2007).

61. Hoffman, B. M., Lukoyanov, D., Yang, Z. Y., Dean, D. R. \& Seefeldt, L. C. Mechanism of nitrogen fixation by nitrogenase: the next stage. Chem. Rev. 114, 4041-4062 (2014).

62. Ogata, H. et al. Activation process of [NiFe] hydrogenase elucidated by highresolution $\mathrm{X}$-ray analyses: conversion of the ready to the unready state. Structure 13, 1-8 (2005).

63. Higuchi, Y., Ogata, H., Miki, K., Yasuoka, N. \& Yagi, T. Removal of the bridging ligand atom at the $\mathrm{Ni}-\mathrm{Fe}$ active site of [NiFe] hydrogenase upon reduction with $\mathrm{H}_{2}$, as revealed by X-ray structure analysis at $1.4 \AA$ resolution. Structure 7, 549-556 (1999).

\section{Acknowledgements}

We thank Patricia Malkowski (MPI-CEC) for her assistance with the ${ }^{57} \mathrm{Fe}[\mathrm{NiFe}]-$ hydrogenase sample preparation. This work was supported by the DOE Office of Biological and Environmental Research (S.P.C.), NIH grant GM-65440 (S.P.C.), DOE grant DEFG02-90ER14146 (T.B.R.), BMBF (03SF0355C), EU/Energy Network project SOLARH2 (FP7 contract 212508), DFG-funded Cluster of Excellence RESOLV (EXC1069), Max Planck Society (W.L., T.K., M.v.G., F.N. and H.O.) and the DFG-funded 'Unifying Concepts in Catalysis' (UniCat) initiative (V.P.). Use of SPring-8 is supported by JASRI (proposals 2012A0032-2014B1032) and RIKEN (proposals 20120107, 20130022 and 20140033).

\section{Author contributions}

H.O. prepared the ${ }^{57} \mathrm{Fe}$-labelled [NiFe]-hydrogenase samples. H.W., L.B.G., A.D.S., Y.Y. Y.T. and S.P.C. measured and analysed the NRVS spectra. T.B.R. and D.S. prepared and characterized the model complexes. V.P. performed the DFT calculations on the model complexes. T.K., M.v.G., F.N. performed the DFT calculations on [NiFe]-hydrogenase. H.O., T.K., H.W., D.S., V.P., M.v.G., W.L. and S.P.C. wrote the manuscript. S.P.C. designed and coordinated the project.

\section{Additional information}

Supplementary Information accompanies this paper at http://www.nature.com/ naturecommunications

Competing financial interests: The authors declare no competing financial interests. 
Reprints and permission information is available online at http://npg.nature.com/ reprintsandpermissions/

How to cite this article: Ogata, $\mathrm{H}$. et al. Hydride bridge in [NiFe]-hydrogenase observed by nuclear resonance vibrational spectroscopy. Nat. Commun. 6:7890 doi: $10.1038 /$ ncomms8890 (2015) (c) (i) This work is licensed under a Creative Commons Attribution 4.0 International License. The images or other third party material in this article are included in the article's Creative Commons license, unless indicated otherwise in the credit line; if the material is not included under the Creative Commons license, users will need to obtain permission from the license holder to reproduce the material. To view a copy of this license, visit http://creativecommons.org/licenses/by/4.0/ 